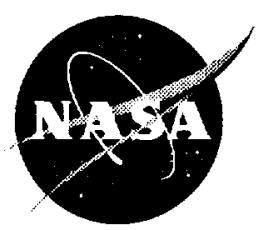

High Power Hall Thrusters

$$
\mu N-20
$$

Robert Jankovsky

Glenn Research Center, Cleveland, Ohio

Sergey Tverdokhlebov

TsNIIMASH Export, Korolev, Moscow, Russia

David Manzella

Dynacs Engineering Company, Inc., Brook Park, Ohio 
The NASA STI Program Office ... in Profile

Since its founding, NASA has been dedicated to the advancement of aeronautics and space science. The NASA Scientific and Technical Information (STI) Program Office plays a key part in helping NASA maintain this important role.

The NASA STI Program Office is operated by Langley Research Center, the Lead Center for NASA's scientific and technical information. The NASA STI Program Office provides access to the NASA STI Database, the largest collection of aeronautical and space science STI in the world. The Program Office is also NASA's institutional mechanism for disseminating the results of its research and development activities. These results are published by NASA in the NASA STI Report Series, which includes the following report types:

- TECHNICAL PUBLICATION. Reports of completed research or a major significant phase of research that present the results of NASA programs and include extensive data or theoretical analysis. Includes compilations of significant scientific and technical data and information deemed to be of continuing reference value. NASA's counterpart of peerreviewed formal professional papers but has less stringent limitations on manuscript length and extent of graphic presentations.

- TECHNICAL MEMORANDUM. Scientific and technical findings that are preliminary or of specialized interest, e.g., quick release reports, working papers, and bibliographies that contain minimal annotation. Does not contain extensive analysis.

- CONTRACTOR REPORT. Scientific and technical findings by NASA-sponsored contractors and grantees.
- CONFERENCE PUBLICATION. Collected papers from scientific and technical conferences, symposia, seminars, or other meetings sponsored or cosponsored by NASA.

- SPECIAL PUBLICATION. Scientific, technical, or historical information from NASA programs, projects, and missions, often concerned with subjects having substantial public interest.

- TECHNICAL TRANSLATION. Englishlanguage translations of foreign scientific and technical material pertinent to NASA's mission.

Specialized services that complement the STI Program Office's diverse offerings include creating custom thesauri, building customized data bases, organizing and publishing research results ... . even providing videos.

For more information about the NASA STI Program Office, see the following:

- Access the NASA STI Program Home Page at $h t t p: / / w w w . s t i . n a s a . g o v$

- E-mail your question via the Internet to help@sti.nasa.gov

- Fax your question to the NASA Access Help Desk at (301) 621-0134

- Telephone the NASA Access Help Desk at (301) 621-0390

- Write to: NASA Access Help Desk NASA Center for AeroSpace Information 7121 Standard Drive Hanover, MD 21076 
NASA/TM-1999-209436

\title{
High Power Hall Thrusters
}

\author{
Robert Jankovsky \\ Glenn Research Center, Cleveland, Ohio \\ Sergey Tverdokhlebov \\ TsNIIMASH Export, Korolev, Moscow, Russia \\ David Manzella \\ Dynacs Engineering Company, Inc., Brook Park, Ohio
}

Prepared for the 35th Joint Propulsion Conference and Exhibit cosponsored by AIAA, ASME, SAE, and ASEE Los Angeles, California, June 20-24, 1999

National Aeronautics and Space Administration

Glenn Research Center 
Available from

NASA Center for Aerospace Information 7121 Standard Drive

Hanover, MD 21076

Price Code: A03
National Technical Information Service 5285 Port Royal Road Springfield, VA 22100 Price Code: A03 


\title{
High Power Hall Thrusters
}

\author{
Robert Jankovsky \\ National Aeronautics and Space Administration \\ Glenn Research Center \\ 21000 Brookpark Rd \\ Cleveland, Ohio 44135 \\ Sergey Tverdokhlebov \\ TsNIIMASH Export \\ 4 Pionerskaya St \\ Korolev, Moscow Region \\ 141070, Russia \\ David Manzella \\ Dynacs Engineering Company Inc. \\ 2001 Aerospace Parkway \\ Brook Park, Ohio 44142
}

\begin{abstract}
$\underline{\text { Abstract }}$
The development of Hall thrusters with powers ranging from tens of kilowatts to in excess of one hundred kilowatts is considered based on renewed interest in high power, high thrust electric propulsion applications. An approach to develop such thrusters based on previous experience is discussed. It is shown that the previous experimental data taken with thrusters of $10 \mathrm{~kW}$ input power and less can be used. Potential mass savings due to the design of high power Hall thrusters are discussed. Both xenon and alternate thruster propellant are considered. as are technological issues that will challenge the design of high power Hall thrusters. Finally, the implications of such a development effort with regard to ground testing and spacecraft integration issues are discussed.
\end{abstract}

\section{Introduction}

It has long been the goal of both US and Russian scientists to use high power electric propulsion for primary spacecraft propulsion. Missions to Mars, reusable space tugs, and other propulsion intensive missions have all been considered since the early 1960 's. The opportunities to conduct these missions have never arisen due to the lack of onboard spacecraft power. Additionally, due to a combination of technical problems, political pressure, and unfortunate timing the possibility for space nuclear power has been virtually eliminated. As a result the major electric propulsion development efforts over the last several decades has concentrated on devices with powers of only a few kilowatts or less.

With regard to Hall thrusters, these efforts, which were for the most part conducted in what was then the Soviet Union, have resulted in successful operational deployment of these devices for stationkeeping purposes on Soviet and later Russian spacecraft. The early engines operated at $0.6 \mathrm{~kW}$ and later engines operated at $1.35 \mathrm{~kW}$. Since the end of the cold war this very successful Hall thruster technology became available to the rest of the world. The first implementation of this technology on a Western spacecraft occurred in 1998 when a device of the anode layer type (TAL), derated for operation at $0.6 \mathrm{~kW}$, was flown on a U.S. government experimental spacecraft. There are a multitude of additional spacecraft being planned that will use higher power Hall thrusters in the near future. The highest power system being developed for near term flight is a $5 \mathrm{~kW}$ system utilizing a TI60E SPT type engine slated for flight in early 2000.

Spacecraft power system designs have steadily evolved. Spacecraft with power levels approaching $20 \mathrm{~kW}$ are currently being implemented. As a result. electric propulsion. and specifically Hall thrusters, are being considered once again for high total impulse missions that have not been considered since the possibility for space nuclear power died.

The combination of advanced power systems and advanced orbital trajectories have mission designers emphasizing a significant need for high power Hall thruster technology with a high ratio of thrust-to-power. This technology promises the possibility of significant reductions in launch mass making new missions possible with the existing launch vehicle fleet. Non-nuclear trans-lunar and 
trans-Mars injections, space solar power satellites, Space Station Reboost. LEO-GEO transfers in less than 90 days are a few examples of these new missions. ${ }^{1.2 .+4}$ The thruster power levels required for these missions range from 30 to $100 \mathrm{~kW}$, in excess of what is currently available. As a result. the objective of this paper is to give preliminary consideration to the general issues associated with the development of high power Hall thrusters, suggest reasonable limits for near term extrapolation of state-of-the-art (SOA) Hall technology, and to suggest a development path for the even higher power thrusters.

\section{Nomenclature}

$T$ thrust

$P$ power

I ion current

$J_{i}$ ion current density

$\mu_{0}$ permeability of free space

$v_{i}$ average ion exhaust velocity

m mass flowrate (use typical sign with upper dot)

e electron charge

$M$, molecular wt. ion

B magnetic field strength

$I_{H}$ Hall current caused by electric drift of electrons

D average diameter of thruster channel

$r_{i}$ ion Larmour radius

$\mathrm{V}_{\mathrm{d}}$ discharge voltage

b. channel width

$I_{d}$ discharge current

$j_{k}$ electron current density

$\mathrm{k}_{1}$ constant

$\mathrm{k}_{2}$ constant

$\mathrm{S}_{\mathrm{ch}}$ channel cross section area

$I_{m}$ equivalent mass flow rate in current units

$\Phi_{\mathrm{cr}}$ electron cyclotron frequency

$v_{i a}$ electron-neutral collision frequency

\section{Background}

There is limited published data relating to the performance of high-power Hall devices. Those data that are available were taken with laboratory model hardware and are generally not comprehensive in nature. However, a review of this work indicates the current state-of-the-art with respect to high power Hall thrusters. Beginning in the early 1980's laboratory models of high power xenon stationary plasma thrusters with outer discharge chamber diameters up to $290 \mathrm{~mm}$ were developed and tested in Russia at Fakel in cooperation with Moscow Aviation Institute (MAI) and the Kurchatov Institute. ${ }^{5.6}$ At the same time large-scale anode layer thrusters (TALs) were developed and tested in Russia at TsNIIMASH in cooperation with RSC "Energia." Initially these TAL tests investigated bismuth as a propellant. ${ }^{7}$ Later tests considered xenon as the propellant. In both cases the objective of these tests was to demonstrate operation with high specific impulse. ${ }^{8}$ More recently the performance of one of these high power TALs developed at TsNIIMASH for operation on xenon, given the designation TM-50, was evaluated at NASA GRC for operation in a high thrust, low specific impulse mode. ${ }^{y}$ Most recently, Jankovsky et al. reported the preliminary results from testing an SPT type thruster, designated the T-220 at NASA GRC." "This thruster was developed in the United States by TRW in cooperation with Space Power Incorporated. A portion of these data encompassing the range of operation for each these devices is summarized in the Table 1 and shown graphically in Figure 1.

\section{Physical Limitations}

The operational features of low-power thrusters with closed electron drift have previously been comprehensively investigated. Therefore the analysis below focuses on the physical constraints limiting the maximum power of a single Hall thruster. Arrays of lower power Hall thruster are an alternate strategy for obtaining high power Hall thruster propulsion systems, however neither this approach nor multi-channel Hall thrusters are considered in this analysis. Both of these approaches may offer certain advantages, but they are evident design derivatives from the single thruster channel which is considered.

The general desire to evaluate high-power Hall thrusters assumes their capability to operate with the highest possible thrust-to-power ratio. Because this ratio is inversely proportional to the average ion exhaust velocity, $\boldsymbol{T} / \boldsymbol{P} \sim \mathbf{1} / \mathrm{v}_{i}$, operation with relatively low specific impulse, $\boldsymbol{I}_{s p}$, at low discharge voltages is preferable. Thus a thruster's ability to accelerate a maximum ion current $I_{i}$ is of great interest. Correspondingly for a thruster of given cross section. the maximum achievable ion current density $J_{i}$ represents a physical constraint which must be considered.

The maximum permissible value for $\boldsymbol{J}_{i}$ in Hall thrusters can be estimated by utilizing the magnetohydrodynamic approximation for the momentum flux density of ions accelerated by Hall current. This approximation, first suggested by $\mathrm{A}$. Zharinov and Y. Popov over thirty years ago, neglects electron pressure and the influence of self-induced magnetic field: 


\section{$J_{i} M_{i} v_{i} / e \leq B^{2} / 2 \mu_{v}$}

Therefore, to increase ion current it is necessary to increase the cross section of the thruster channel or increase the magnetic field strength. When the magnetic field is increased to satisfy this condition the ion current density is proportional to the Hall drift current $\boldsymbol{I}_{\boldsymbol{H}}$ :

$$
J_{i} \approx I_{H} / 2 \pi D r_{i}
$$

Where $\boldsymbol{D}$ is the average diameter of thruster discharge chamber and $\boldsymbol{r}_{i}$ is the ion Larmour or gyroradius.

Because of the electron losses to the walls. anomalous electron mobility caused by the scattering attributed to oscillations, and due to azimuthal non-uniformity's, the Hall current value is always less than its theoretical maximum.

$$
I_{H}=\int_{u}^{x_{u}} j_{i} \boldsymbol{\sigma}_{c u}\left(1 / v_{w}\right) d x
$$

Another potential limit to scaling of Hall thrusters is the distortion of the external magnetic field, caused by the diamagnetic influence of the Hall current. If the self-induced magnetic field of the Hall current is significant, under certain conditions, a significant distortion of the electric field distribution along the thruster channel and subsequent unpredictable thruster performance may develop. Although all aspects of this phenomena are not well understood, the strong gradient of magnetic field in the thruster channel may help to minimize this distortion.

Another potential limit to the maximum discharge current is Joule heating of the anode caused by the back-streaming of electrons. The average electron energy at low mass flow rates for a TAL may be as high as $\boldsymbol{e} \boldsymbol{V}_{d} / \mathbf{5}$. This requires up to $20 \%$ of the input power be radiated or conducted away from the anode. However, generally as the neutral density increases the average electron energy decreases, but the total power increases and the anode energy dissipation remains constant over a relatively wide range of thruster operation. This is referred to as the "power plateau". Further increases in propellant flow rate above this "power plateau" results in a substantial increase in electron back-streaming evident by large increases in discharge current with incremental flow rate increases. Substantial flow rate, or current increase, in this regime of operation are generally limited by the thermal design of the anode which serves as a practical limit for high power operation of a given device.
The choice of propellant also impacts the necessary ion current density for efficient thruster operation. While the previously presented equation shows that a lower magnetic field is all that is required to accelerate the same flux of lighter ions as compared to a heavier ion, an acceptable value of propellant utilization (or efficiency) requires higher current density for the lighter propellant." Thus, while the thermal limitations of a given thruster are not affected by the choice of propellant, the necessity to increase the discharge current to maintain the efficiency while operating with lighter propellants does reduce the margin with respect to the thermal design. The increase in discharge current also results in a reduction in the attainable discharge voltage at fixed power.

Because these considerations are general in nature they are applicable to both SPT and TALtype Hall thrusters. A quasi-neutral mode of operation is assumed, and the so called vacuum mode of TAL operation which has been previously described by others ${ }^{12}$ is not considered primarily due to the unfavorable thrust-to-power ratio encountered during operation in this mode.

\section{Design Parameters}

Simple correlations between power and size of large-scale Hall thrusters can be easily made based on existing laboratory, engineering and flight models of SPTs and TALs. To assess the target performances for high power Hall thruster development comparative analysis was made with use of published data ${ }^{7-12.13 .14 .15}$ on power, characteristic size and mass of 6 SPT models and 5 TAL models. For comparison convenience the values of power and mass flow rates were taken from data corresponding to an $\boldsymbol{I}_{s p}$ of approximately $2500 \mathrm{sec}$. Also, for convenience an average diameter of the thruster channel was used instead of the outer diameter which is the convention in SPT-related publications. Thrusters with average diameter of 38-250 $\mathrm{mm}$ were considered.

Figure 2 illustrates the general scaling trend of Hall devices as power increases with channel size. For a discharge chamber with an average diameter of $400 \mathrm{~mm}$ power levels of $37 \mathrm{~kW}$ and $48 \mathrm{~kW}$ would be predicted for operation at 2500 second specific impulse with an SPT and TAL respectively. This result is consistent with the fact that TAL is characteristically smaller device than SPT for a given power level (for example an SPT100 and TAL D-55 have the same nominal power capability). As is also seen in this figure with data from TAL testing, by increasing the specific 
impulse requirement for a given thruster size the maximum predicted power level also increases, however at the expense of thrust. This dependence of specific impulse on discharge voltage is predictable based on the mass flow rate, thruster dimensions, and the exchange parameter $\xi$. defined as the ratio of the discharge current divided by the current equivalent mass flow rate for a singly ionized propellant.

With some mathematical manipulation one can write the thruster power in terms of the discharge voltage. the exchange parameter, the thruster diameter, and several variables depending on the area and width of the discharge chamber:

$$
\begin{gathered}
P \approx k_{1} D^{2}\left(I+k_{2} / D\right) \xi, V_{d} \\
\text { where } k_{I} \propto \dot{m} / S_{c h} \text { and } k_{2} \propto \dot{m} / D
\end{gathered}
$$

In SPT thrusters the parameter of exchange $\xi$, has been shown to increase linearly with the increased channel average diameter $D$ and width $\boldsymbol{b}_{\boldsymbol{c}}$. For instance, with an increase of average diameter from $50 \mathrm{~mm}$ to $250 \mathrm{~mm}$, the increase in the exchange parameter from 0.9 to 1.4 was reported. ${ }^{16}$ However, the ratio of $\dot{m} / S_{c h}$ remained constant. Previously it has been suggested that the ratio of $\dot{\boldsymbol{m}} / \boldsymbol{D}$ remains constant with thruster size, ${ }^{16.17}$ however, based on the data shown in Figure 3 there is some variation with thruster size and. therefore. it is believed that in general $\dot{m} / D \neq$ constant. More specifically, those cases in which $\dot{\boldsymbol{m}} \boldsymbol{D}$ is held constant are not of significant interest because they require an increase of the thruster diameter while holding other discharge chamber parameters constant, thus sacrificing performance. Finally. while it appears that for the most part $\dot{m} / S_{c h}$ is constant it is possible to increase this ratio at the expense of thruster lifetime.

Similar considerations may be used to estimate thruster mass. The required magnetic field strength $\mathbf{B}$ is directly proportional to the discharge current $\boldsymbol{I}_{d}$ for a wide range of mass flow rates (for discharge voltages in the range of 200-600 V). The mass of the magnetic system usually represents about $75-80 \%$ of total thruster mass. The difference between the mass value for existing engineering models and the targets for flight models was also considered to estimate the thruster mass reduction trend during the development efforts from laboratory to flight status. The values of thruster mass were corrected to exclude cathode(s) and orifice block. The results are presented in the Figure 4.

The mass reduction trend is generally similar for both SPT and TAL. so the approximate values of 50 and $40 \mathrm{~kg}$ may be predicted for both an SPT and TAL $50 \mathrm{~kW}, 2500 \mathrm{sec}$ laboratory and flightweight thruster. Thruster specific mass goes down with the increase of power. Therefore, for comparison purposes, it can be seen that a single $50 \mathrm{~kW}$ thruster would be $30 \%$ lighter than ten $5 \mathrm{~kW}$ thrusters.

A simple parametrical approach like the one described above does not involve a thorough consideration of all the physical constraints such as critical ion current density or thruster thermal mode. Nevertheless, it is useful for initial engineering estimates and it gives an opportunity to imagine the sequence of attempts to employ the traditional Hall thruster design in the extreme conditions. For instance. it may be shown that a $100 \mathrm{~kW}$ Hall thruster with a specific impulse of $1600 \mathrm{~s}$ (300 V for xenon) may be as large as one meter in average diameter.

\section{Technological Issues of Thruster Design}

The development of high-power Hall thrusters as well as of any large-scale device represents certain design and technological challenges. While there are numerous possible design configurations for Hall-current devices only the most general characteristics will be considered. First. a linear increase in Hall thruster dimensions involves certain difficulties with providing an azimuthally homogeneous magnetic field and gas distribution in the thruster channel required for normal drift motion of electrons. Local non-uniformity's may result in potential eccentricities in the thruster plume. Potential reasons include, but are not limited to, local changes in the discharge chamber walls conductivity (issue of ceramic material homogeneity), mechanical alignment, and cathode location. These may lead to several effects such as non-symmetric wear of the discharge chamber walls and shifts in the thrust vector. All these features that are generally inherent to any size of Hall thrusters may be strongly amplified while occurring in a large design.

Increase of thruster size may also complicate thruster design from a thermal-mechanical standpoint. This is because absolute values of linear expansions expected for thermal stressed elements of the thruster are proportional to its average diameter and are comparable with the characteristic length of acceleration zone. Another significant issue is the temperature gradients originating across the channel walls. This will necessitate a transient as well as steady-state thermal analysis of critical components such as thruster ceramics. A preliminary consideration has already been given to transient analysis of high power hall thrusters. It has been demonstrated experimentally that it may take multiple hours to reach thermal equilibrium. In one experiment a non-monotonic increase in temperature was observed during a transient mode. 
This indicates potentially different contribution in time of the thermal conductivity and radiation mechanisms of heat exchange. Corresponding changes in performances may accompany these different thermal regimes, which therefore, will need to be a concern of future high power designs.

Generally, if the approximate heat flux distribution in the thruster chamber is known the simulation of a thruster thermal mode may be done with use of finite elements methods. The only problem is to determine a boundary conditions on heat-exchanging and radiating surfaces. As for detailed thermal analysis of a thruster, one of the remaining uncertainties is associated with the correct determination of the energy associated with plume emission in the VUV range.

Another issue is the development of a special propellant insulator. Because of increased voltages, large mass flow rates, high anode temperature, presence of high frequency electric field and residual magnetic field, etc., a new reliable design is required. So, it is clear that there are practical imitations with regard how large high power Hall thrusters can be made, based on the individual components used to make these thrusters which will have to be addressed in order to permit the development of high power Hall thrusters.

\section{Propellant}

Propellant selection for High Power Hall is of critical importance. Xenon is the only propellant under utilization in the current and near term missions employing Hall thruster propulsion. While typical magnitudes of propellant mass required for projected telecommunication satellites with 1 to $5 \mathrm{~kW}$ Hall thrusters does not exceed $100 \mathrm{~kg}$, hundred--kW space missions would require tons of propellant. Assuming total thrust time for two round trips to a high elliptical point of trans-planet injection, utilizing $500 \mathrm{~kW}$ of solar electric power, a propulsion system consisting of $10 \mathrm{Hall}$ thrusters consuming $50 \mathrm{~kW}$ power each could be imagined. Such thrusters might have a flow rate of $100 \mathrm{mg} / \mathrm{s}$ of xenon each with a specific impulse of $2500 \mathrm{sec}$. For this mission, a propellant mass of $\sim 30$ metric tons is required. Availability of xenon supply, therefore, becomes one of the major concerns. Potential alternatives under discussion include krypton, xenon-krypton mixtures or condensable metal propellants.

From a purely thruster physics standpoint, it is clear that to maximize thrust-to-power the best choice of propellant is the highest molecular weight element that that does not pose an excessively high cost for ionization. A few examples of alternate propellants are in Table 2. For comparison purposes changes in thruster efficiency with alternate propellants is not included. While only considering the thruster physics in selecting a propellant is not a recommended approach, it is the basis from which initial considerations should start. From the initial thruster physics basis other considerations such as propellant management, spacecraft contamination. ground testing, and environmental impact can be traded against trip time, spacecraft power system and launch vehicle for each application. The trade for a geostationary spacecraft that desires to do low Earth orbit to geostationary orbit transfer with a Hall thruster or the International Space Station which desires to use a Hall thruster for reboost may be quite different than a manned mission to Mars or a trans-Neptune stage.

If a propellant other than xenon is pursued several issues will need to be addresses. Here we will qualitatively consider only some of them for the most commonly considered alternative, krypton. The first is with respect to the impact of utilizing krypton as a propellant which may seem attractive based on it similarity to xenon. In practice, however, the higher ionization potential and lower atomic weight of krypton lead to substantial decreases in Hall thruster performance. Preliminary investigations conducted with singlestage SPTs and TALs operated with krypton demonstrated $15-20 \%$ less efficiency than with xenon. ${ }^{18}$ Even with a greater than $50 \%$ increase in mass flow rate and subsequent increase in the discharge current the expected efficiency on krypton in the specific impulse range of $2000-2500 \mathrm{sec}$ will probably not be in excess of $40-45 \%$. The penalty associated with the operation at the increased discharge currents is a higher thruster thermal load as compared with operation on xenon.

Mixtures of gases such as xenon and krypton have also been previously considered. For our consideration, however, the extra energy dissipation in the thruster structure may still be the limiting technical issue because it constrains the maximum input power of a thruster with given size. Certainly, the addition of $10-50 \%$ molar impurity of xenon to a krypton propellant will result in improvement of the thruster performance as compared to pure krypton. However, no principal "resonant" phenomenon facilitating the increase of partial krypton utilization efficiency with xenon are expected. This is verified by limited experimentation which demonstrated the additive character of xenon's contribution to thrust and efficiency. Therefore, the attractiveness of use of the 
xenon-krypton mixture ${ }^{*}$ to resolve a cost and propellant availability issues is still in direct proportion of xenon fraction used. Ultimately either cost or other systems considerations are likely to drive the propellant selection. However. at this time preliminary analysis based on combined consideration of cost/performances/system integration impacts shows that the most reasonable and cost effective approach for the nearest development of high-power Hall thruster is to complete the evaluation and test program of hardware on xenon. Also a dedicated analysis which gives careful consideration to the benefits vs. environmental impacts of development of metal propellant systems should be undertaken.

\section{Test \& Integration}

The testing and integration of high power Hall thrusters will have an impact on the results of any design consideration for this type of thruster. Of course, the magnitude of the impact is dependent on such things as thruster type and propellant selection (i.e., non condensable versus condensable). Also, the possibility for things like plume impingement onto spacecraft surfaces, or contamination of sensitive optical surfaces are highly dependent on a particular geometry and spacecraft configuration. In the following discussions these issues will be considered in general for a single thruster. If an array of thrusters is utilized additional complications, beyond those discussed here may be manifest.

Although it may be possible to design a Hall thruster for a given application with favorable operational characteristics in space, if the design cannot be qualified and acceptance tested in an acceptable fashion on the ground the design is of questionable utility. As a result. the issues related to the ground testing of large Hall thrusters are of primary importance. The main technical consideration with regard to ground testing is what level of vacuum is needed within the ground test facility to adequately simulate the environment in which the thruster would operate in space. The ability of a test facility to sustain a given vacuum pressure is related to its pumping speed. Typically a surface which will condense the propellant upon it is used as the pump. this often times requires cryogenic temperatures for gases such as krypton and xenon.

\footnotetext{
- Note that obtaining of a pure Xe-Kr mixture may be even more expensive procedare than direct production of $X e$ from initial product of industrial air -separating facilities, comraining $0.15 .0 .25 \%$ of $x$ enom and krypton.
}

Previously, for consideration of propellant selection, a xenon flow rate of $100 \mathrm{mg} / \mathrm{s}$ was considered as a possibility for a single $50 \mathrm{~kW}$ thruster with a specific impulse of $2500 \mathrm{sec}$. For thrusters of the SPT type the facility pressure was shown to have an effect on the measured performance at pressures above $2 \times 10^{-5}$ torr. $^{15}$ In order for this effect, thought to be caused by ingestion of background gas into the discharge chamber of the engine, to be insignificant, a xenon pumping speed in excess of 600,000 liters per second would be required. While this pumping speed is within the range of currently existing electric propulsion test facilities, those with a order of magnitude higher pumping speeds are not. Additionally. thrusters of the traditional anode layer type tend to have a smaller cross sectional area at the exit plane than do SPT type thrusters. As a result it is likely that chamber pressure does not have an effect on performance until slightly higher pressures are reached.

These considerations have focused on the effect of mass flow rate, which to first order determines the current in a Hall thruster and on vacuum facility background pressure during testing. When discussing high power operation the effect of discharge voltage should also be considered. As discharge voltage is increased the effect of the ingested background gas on performance changes. This is because at higher voltage, the ingested neutral gas has a lower probability of diffusing completely through the acceleration zone within the discharge chamber before being ionized by electron impact and subsequently accelerated itself. Therefore these ingested, ionized, and subsequently accelerated background atoms do not produce as much thrust as those propellant atoms introduced at the rear of the discharge chamber through the anode. This is the basis for the varying effect of background pressure on performance with discharge voltage. The over riding consideration is that in any ground test the effect of the finite background pressure must be adequately understood. Corrections can be made to account for this effect, but if the corrections are not adequate a real possibility exists for thruster operation in space to be significantly different than during qualification and ground testing.

A second consideration with regard to testing of high power Hall thrusters is the ability to adequately address relevant integration issues. While these individual issues will subsequently be considered, a significant number of these are related to the distribution of effluent in the plume. Background gas within a test facility during thruster operation may charge exchange with energetic plume ions affecting the distribution and composition of the plasma generated by the engine. While estimates of this effect can be made 
based on known charge exchange cross sections, for example, experimental evidence indicates that even at pressures below $2 \times 10^{-6}$ torr this phenomena is still significant for those regions of the plume at large angle to the direction of thrust. ${ }^{19}$ For the same $100 \mathrm{mg} / \mathrm{s}$ Hall thruster considered above, this corresponds to a $6,000,000 \mathrm{l} / \mathrm{s}$ required pumping speed which, as previously stated, is not currentiy possible in existing electric propulsion test facilities.

Another testing issue of serious consequence is related to sputtering of the surfaces subjected to direct ion impingement within the test facility. Conceptually this issue is easy to visualize. The engine is designed to produce high energy particles which can travel at velocities well in excess of $20 \mathrm{~km} / \mathrm{s}$. Due to the extreme energetic nature of these particles, upon impact with a surface there is a finite probability that they will remove or sputter a portion of the parent material. After long term bombardment of this type the magnitude of material liberated can become quite substantial. For this reason, sputter resistant materials such as graphite are often used as beam targets. The erosion of the facility itself posses no real consequence to the test, as long as the actual structural integrity of the facility is not compromised, however, the sputtered material will redeposit elsewhere within the facility, including on the test hardware with potentially adverse results. This effect can be minimized through careful design of targets and baffles, but is certainly a significant issue with respect to the long term testing of high power Hall thrusters. To illustrate the magnitude of this effect, again consider the $50 \mathrm{~kW}$ thruster with a xenon mass flow rate of $100 \mathrm{mg} / \mathrm{s}$. For a graphite target at $5 \mathrm{~m}$ from the exit plane of the engine the surface would be eroded $0.1 \mathrm{~mm}$ after $5000 \mathrm{hrs}$ of operation. If the surface was stainless steel it would be eroded to a depth of $0.6 \mathrm{~mm}$. While this may not seem substantial the total amount of graphite sputtered throughout the tank would be as much as $46 \mathrm{~kg}$ and for steel in excess of $1000 \mathrm{~kg}$. Clearly the redeposition of this material may be a significant concern for the test hardware.

The integration issues associated with high power Hall thrusters are not significantly different than those associated with lower power Hall thrusters. although the impact on a particular spacecraft may be considerably greater due to the larger size and higher fluxes. Direct impingement of particles accelerated out the engine transfer both momentum and thermal energy. For high power thrusters this issue will likely be minimized through spacecraft design, but this certainly will be an integration issue worthy of consideration.
Another issue of potentially significant impact from a spacecraft integration issue is the accommodation of the waste heat generated during thruster operation. A thruster with a reasonably efficient thermal design may still need to reject $25 \%$ of its input power as thermal energy. Minimizing the effect of the conducted and radiated heat on the spacecraft will be a significant design challenge for the high power Hall thruster spacecraft integration specialist.

There are a number of additional issues for consideration from a spacecraft integration perspective. These include the possibility of an off axis thrust vector which could vary in time. If an engine does produce a time varying force in a non desirable direction, the impact on a spacecraft's attitude control system maybe significant. Other issues include the effect of radiated electromagnetic emissions produced by the plasma generated within the operating high power Hall thruster. While this has proven to be a manageable issue for lower power thrusters, the way in which this scales to higher powers remains unknown. Finally, such things as contamination of sensitive surfaces by deposition of engine erosion products and possible optical interference from the light emitted by the plasma produced within the engine must also be considered.

\section{Discussion}

In order to successfully develop the next generation of high power Hall thrusters it is necessary to consider each of the various topics of consideration both separately and as they relate to one another. With this as a basis. the individual technological aspects of such a program can be appropriately addressed. As previously mentioned there is limited amount of prior data from high power Hall thruster testing. What is noteworthy, however, is that these data were, in general, adequately predicted by previous data obtained with lower power Hall thrusters. This demonstrates the efficacy of extending the current technology in a linear fashion which will likely provide significantly increased performance with a modest outlay of resources. This is primarily enabled by the very substantial body of work on Hall thrusters at power levels of $10 \mathrm{~kW}$ and less.

There are physical limitations which dictate the maximum power or power density possible with Hall thrusters. These limitations which are not accounted for by a scaling type of approach were detailed previously. The most fundamental of these physical limitations is the maximum ion current density possible within the discharge chamber of a 
high power Hall thruster. The value of this limit depends on the propellant and thruster type (i.e.. SPT or TAL), but ultimately determines the size of a thruster for a given power level. Furthermore, due to the annular nature of Hall thrusters, as the size of the thruster is increased to permit higher power. the actual power density or power per diameter of the channel decreases. Due to this fact, as the outer diameter of the Hall thruster is increased in size to accommodate higher power, eventually an ion thruster will theoretically approach the thrust of a Hall thruster for a given thruster diameter. It is difficult to predict where these two curves will intersect because of a sparcity of data, and there also remains a significant number of technical issues to be resolved with regard to the development of large gridded thrusters, but for high thrust/low specific impulse applications it is expected that the Hall thruster will offer higher thrust densities for power levels well in excess of $100 \mathrm{~kW}$. Of course this does not consider a multi channel approach or possible non circular geometries which would substantially increase the thrust density in comparison to a single classic annular discharge chamber. This leads to the conclusion that for thrusters optimized to provide high thrust with voltages on the order of 300 Volts, powers up to $100 \mathrm{~kW}$ could be considered with thruster sizes up to $100 \mathrm{~cm}$ in diameter.

There are however practical limitations with regard to the maximum size of thruster which can be fabricated, these limitations are based on the availability of the necessary ceramics and refractory metals in the sizes needed. While a detailed assessment on the maximum sizes of raw materials were not undertaken, anecdotal experience indicates that even at power levels of $10 \mathrm{~kW}$ one approaches the practical limits of what is currently available. There are alternate strategies which can be adopted. Using multiple pieces in place of what has traditionally been a single piece is an obvious approach. The implications of this with regard to surviving the mechanical loads associated with launch may even be favorable. However, there is a degree of risk associated with such a strategy that will need to be addressed.

The issue of propellant choice is perhaps the single biggest consideration with regard to the direction of future high power Hall thruster development. From a cost to develop, technical and historical basis. the experience currently existing with xenon coupled with favorable performance make this propellant an overwhelmingly preferable choice. Problems with price and availability, however, may make this choice untenable from a cost and logistics standpoint. If other propellants are considered additional development is needed. Some of this could be conducted with smaller, lower power thrusters to minimize cost. The additional issues that will likely be determining factors for propellant choice such as environmental considerations tend to be somewhat political in nature and will not be discussed as part of this paper.

The issues relative to testing will also have a very significant impact on the direction of future high power Hall thruster development. This is primarily because the cost of upgrading the infrastructure of the various electric propulsion test facilities required to test high power Hall thrusters may exceed the cost of the development effort itself. At NASA GRC, which has one of the highest pumping speed dedicated electric propulsion test facility, the pumping speed of xenon is approximately 1 million liters per second. For a pressure of $2 \times 10^{-6}$ torr this corresponds to a flow rate of $17 \mathrm{mg} / \mathrm{s}$ which at 300 Volts is only a $5 \mathrm{~kW}$ thruster. In order to conduct research on high power Hall thrusters at higher pressures the implications of the effect of background pressure will have to be more completely understood.

\section{Concluding Remarks}

In summary, the implications of this study are the following: Based on past data there are performance benefits to be gained by increasing thruster size. The wealth of previous experimental data taken with thrusters of $10 \mathrm{~kW}$ input power and less form an excellent basis upon which to develop higher power Hall thrusters. There is a mass savings in using fewer number of higher power thrusters as compared to a larger number of smaller thrusters to obtain a given power level. The desired propellant is xenon, however from a cost, availability, or system perspective high power Hall thrusters using alternate propellants may be developed requiring a greater development effort. There are practical limitations with regard to how large high power Hall thrusters can be made. Creative engineering can stretch these limits, but ultimately development in the such things as raw material fabrication issues may be required. The requirements of the ground test programs necessitated by the development of high power hall thrusters will represent a real limitation in the practical limit for thruster development. Finally, all these considerations have assumed a traditional linear or incremental development of the technology. History indicates that a technical breakthrough permitting a non linear technology jump is possible and even likely during the development cycle for such engines. If not, even now, Hall thrusters with power levels up to $100 \mathrm{~kW}$ can be considered which will enable missions to Mars, 
reusable space tugs, and other propulsion intensive missions which have been under consideration for decades.

\section{References}

1. Oleson, S.R., Advanced Propulsion for Space Solar Power Satellites, AIAA 99-2872

2. Gefert, L.P, Hack, K.J., Kerslake, T.W., Options for the Human Exploration of Mars using Solar Electric Propulsion. proceedings of the Space Technology and Applications International Forum-1999.

3. Oleson, S.R., Influence of Power System Technology on Electric Propulsion Missions. NASA CR-195419

4. Oleson, S.R.. Myers. R.M., Launch Vehicle and Power Level Impacts of Electric GEO Insertion, AIAA-96-2978

5. Arkhipov, B.A. et al., "Development and Investigation of Characteristics of Increased Power SPT Models", IEPC-93-222, Proceedings of 23-rd International Electric Propulsion Conference, Seattle, September 1993.

8. Arkhipov, B.A. et al., "Investigation of SPT200 Operating Characteristics at Power Levels up to $12 \mathrm{~kW}$, IEPC 97-132, Proceedings of $25^{\text {th }}$ International Electric Propulsion Conference. Cleveland, August 1997.

7. Ageev V.P., Safronov I.N., Tverdokhlebov S.O.: Performance Characteristics and Peculiarities of Two-Stage Accelerator with Anode Layer Operation with Low Voltages and Magnetic Field, Sov. Journal of Appl. Mech.\&Tech. Phys. No. 6, 1987. pp. 3-7.

8. Semenkin, A., Tverdokhlebov. S. et al., "TAL Thruster Technology for Advanced Electric Propulsion Sistem". 96-a-3-26, 20 2 ISTS, May, 1996, Gifu, Japan.

9. D. Jacobson. R. Jankovsky, "Performance Evaluation of a $50 \mathrm{~kW}$ Hall Thruster", AIAA 99-0457, Presented on 37 AIAA Aerospace Sciences Meeting and Exhibit, Reno, January 1999.
10. R.S. Jankovsky, C. McLean, J. McVey, "Preliminary Evaluation of a $10 \mathrm{~kW}$ Hall Thruster". AIAA-99-0456. Presented on 37 AIAA Aerospace Sciences Meeting and Exhibit, Reno, January 1999

11. Melikov. I. et al., Soviet Journal of Technical Physics, 1974. Vol. 44, No3.

12. Zhurin. V. et al., "Phrsics of Closed Drift Thruster", IEPC-97-19i. 25 ${ }^{\text {th }}$ IEPC. August. 1997. Cleveland.

13. Arkhipov. B. et al. "Extending the Range of SPT Operation: Development Status of 300 and 4500 W Thruster". AIAA-Paper. Presented on $32^{\text {nd }}$ Joint Propulsion Conference. Orlando, 1996

14. Gavryshin, V.M., Kim. V. et al.. "Physical and Technical Bases of the Modern SPT Development". IEPC 95-38, Proceedings of $24^{\text {th }}$ International Electric Propulsion Conference, Moscow, 1995.

15. Sankovic, J., Hamley, J., and Haag. T., "Performance evaluation of the Russian SPT100 Thruster at NASA LeRC." AIAA-93-094. September. 1993

16. Bugrova, A. et al., "Scaling Lan's for Integral Performances of SPT", Soviet Journal of Technical Physics. 1991. Vol. 61. No. 6. pp. 35-51

17. Bugrova, A., Kim, V.. "Modern State of Phisical Investigation in the Accelerators with Closed Electron Drift and Extended Acceleration Zone"-Paper in the book: Plasma.

18. Marrese, C. et al., "D-100 Performance and Plume Characterization on Krypton". AIAA-96-2969, 32 ${ }^{\text {nd }}$ AIAA JPC. July, 1996, Lake Buena Vista. FL.

19. Manzella, D. and Sankovic, J "Hall Thruster ion beam Characterization," AIAA-95-2927. July, 1995. 
Table 1: Performance of previously developed laboratory model high power Hall thrusters

\begin{tabular}{|c|c|c|c|c|c|}
\hline Thruster type & $\begin{array}{c}\text { SPT-290 } \\
\text { Ref. 5 }\end{array}$ & $\begin{array}{c}\text { T-220 } \\
\text { Ref. 10 }\end{array}$ & $\begin{array}{c}\text { TAL TM-50 } \\
\text { Ref. 9 }\end{array}$ & $\begin{array}{c}\text { TAL-200 [Bi] } \\
\text { Ref. 7 }\end{array}$ & $\begin{array}{c}\text { SPT-200 } \\
\text { Ref. 6 }\end{array}$ \\
\hline $\begin{array}{c}\text { Average diameter, } \\
\text { mm }\end{array}$ & 250 & 188 & 200 & 200 & 175 \\
\hline Isp range. s & $1500-3000$ & $1500-2400$ & $1500-3300$ & $2000-5200$ & $1500-3000$ \\
\hline Input power. $\mathrm{kW}$ & $12-30$ & $5-11$ & $10-25$ & $10-34$ & $6-11$ \\
\hline Thrust. mN & 1500 & 524 & 1114 & 1130 & 498 \\
\hline Efficiency & 0.7 & 0.62 & 0.66 & 0.67 & 0.63 \\
\hline
\end{tabular}

Table 2: Comparison of alternate elemental propellants

\begin{tabular}{|c|c|c|c|c|}
\hline Element & $\begin{array}{c}\text { Molecular } \\
\text { Weight }\end{array}$ & $\begin{array}{c}\text { First Ionization } \\
\text { Potential, eV }\end{array}$ & $\begin{array}{c}\text { \% Thrust } \\
\text { of Xenon }\end{array}$ & $\begin{array}{c}\text { \% Isp } \\
\text { of Xenon }\end{array}$ \\
\hline Radon & 222 & 10.7 & 130 & 77 \\
\hline Bismuth & 208.98 & 7.3 & 126 & 79 \\
\hline Lead & 207.19 & 7.4 & 126 & 80 \\
\hline Mercury & 200.59 & 10.4 & 124 & 81 \\
\hline Cesium & 132.905 & 3.9 & 101 & 99 \\
\hline Xenon & 131.30 & 12.1 & 100 & 100 \\
\hline Krypton & 83.80 & 14.0 & 80 & 125 \\
\hline Argon & 39.948 & 15.8 & 55 & 181 \\
\hline
\end{tabular}

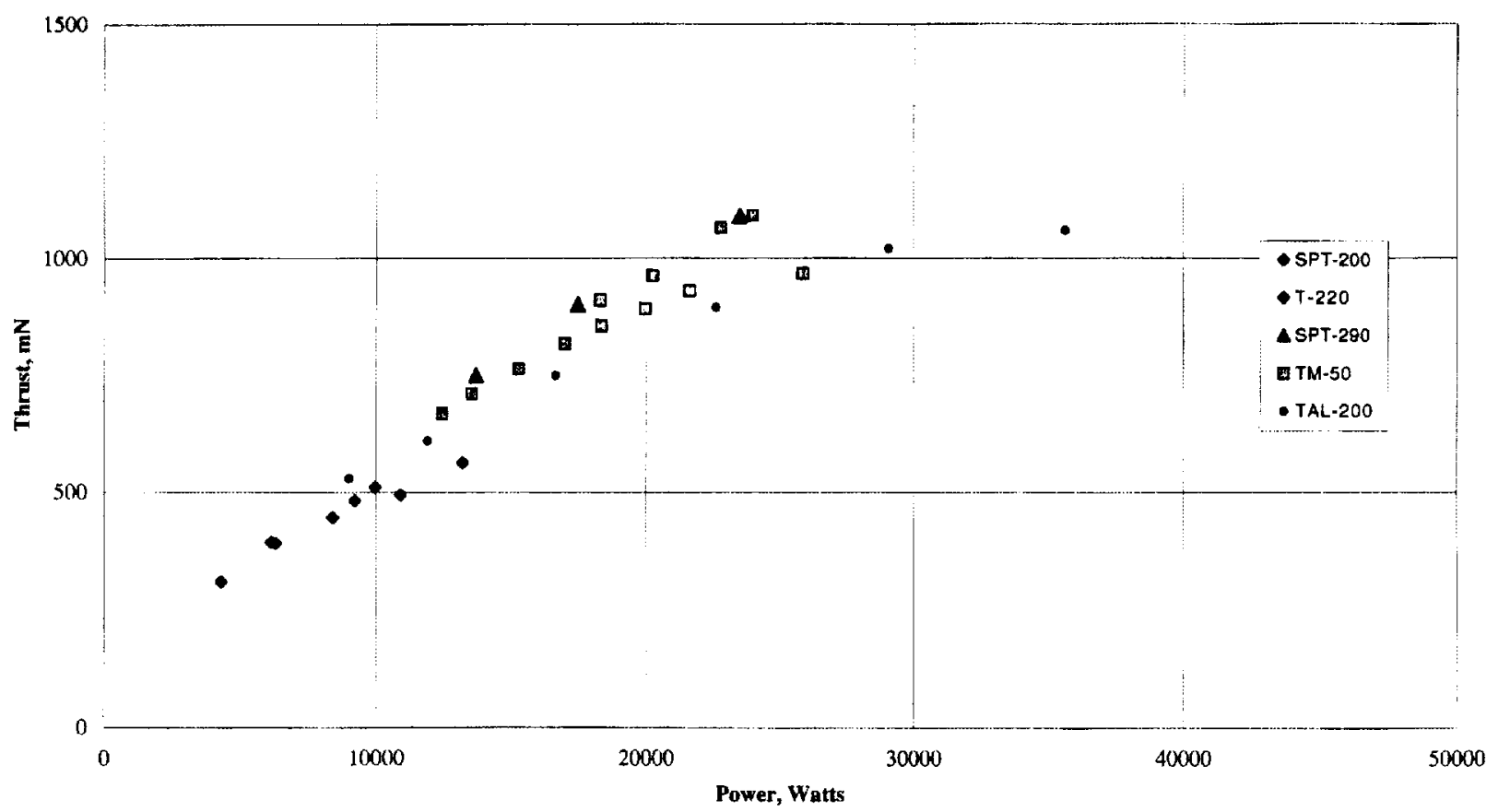

Figure 1: Thrust versus power of previously tested high power Hall thusters 


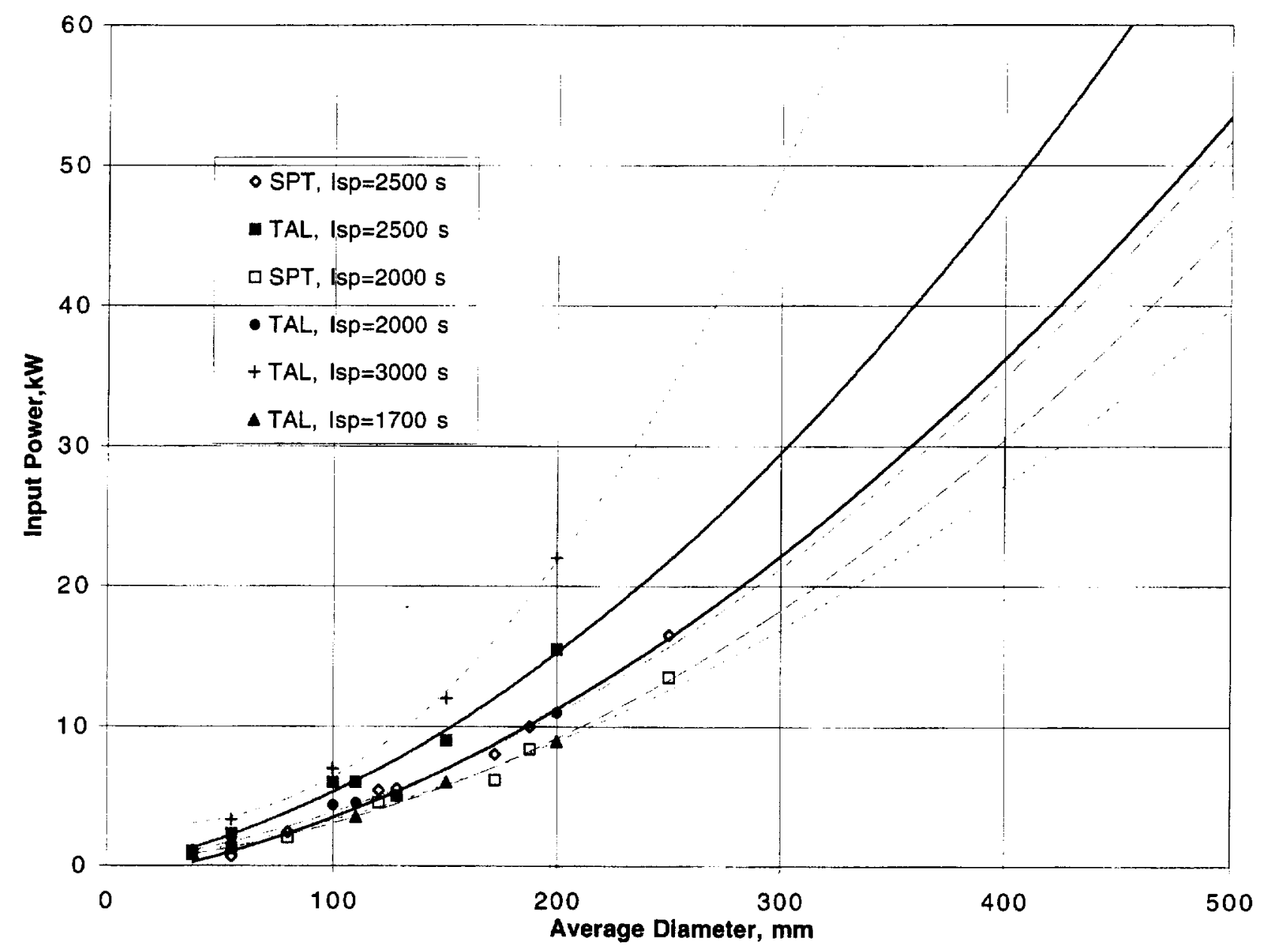

Figure 2: Projected Effect of Input Power and Specific Impulse on Thruster Size 


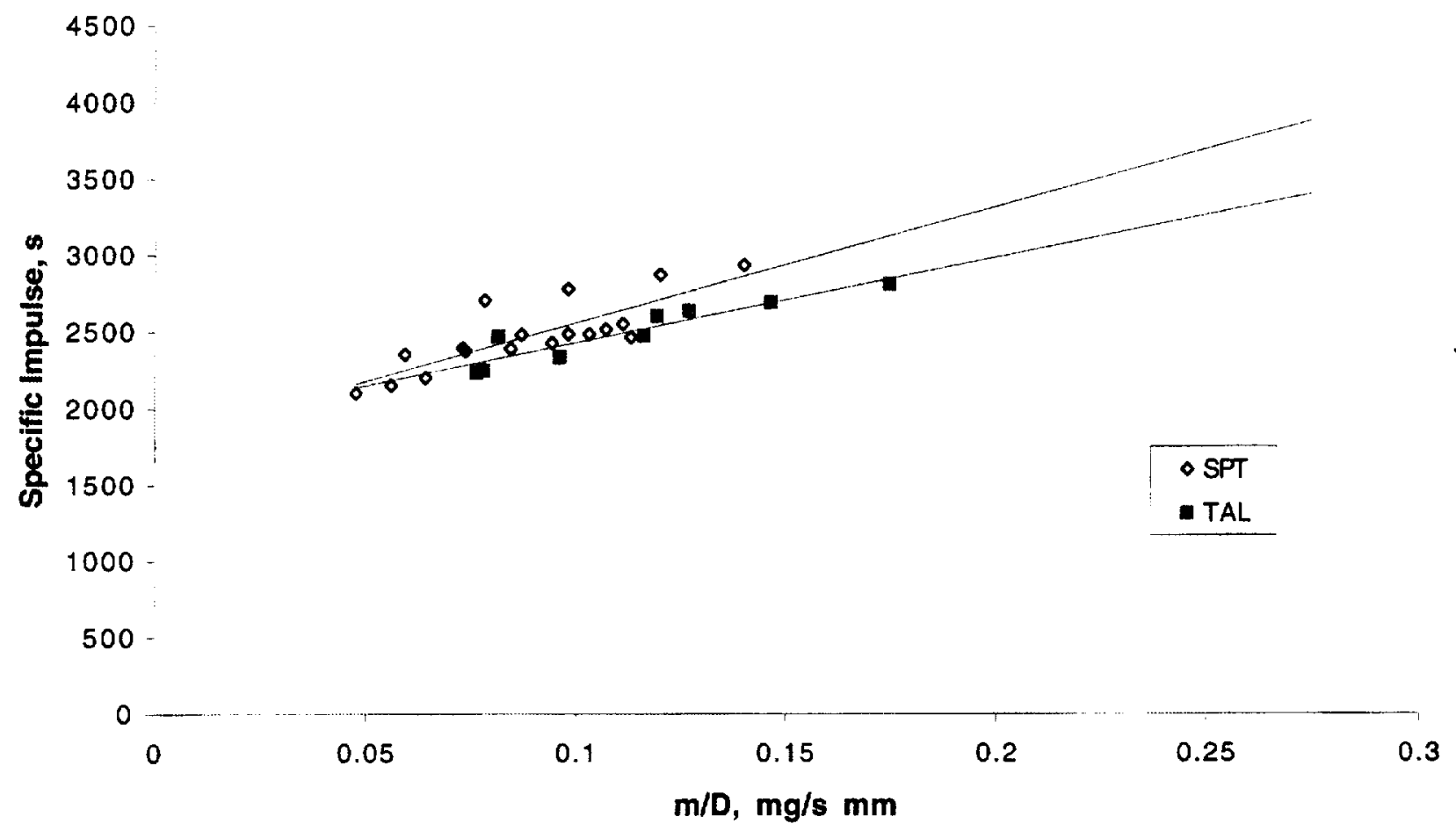

Figure 3: The ratio of mass flow rate divided by average thruster diameter versus specific impulse

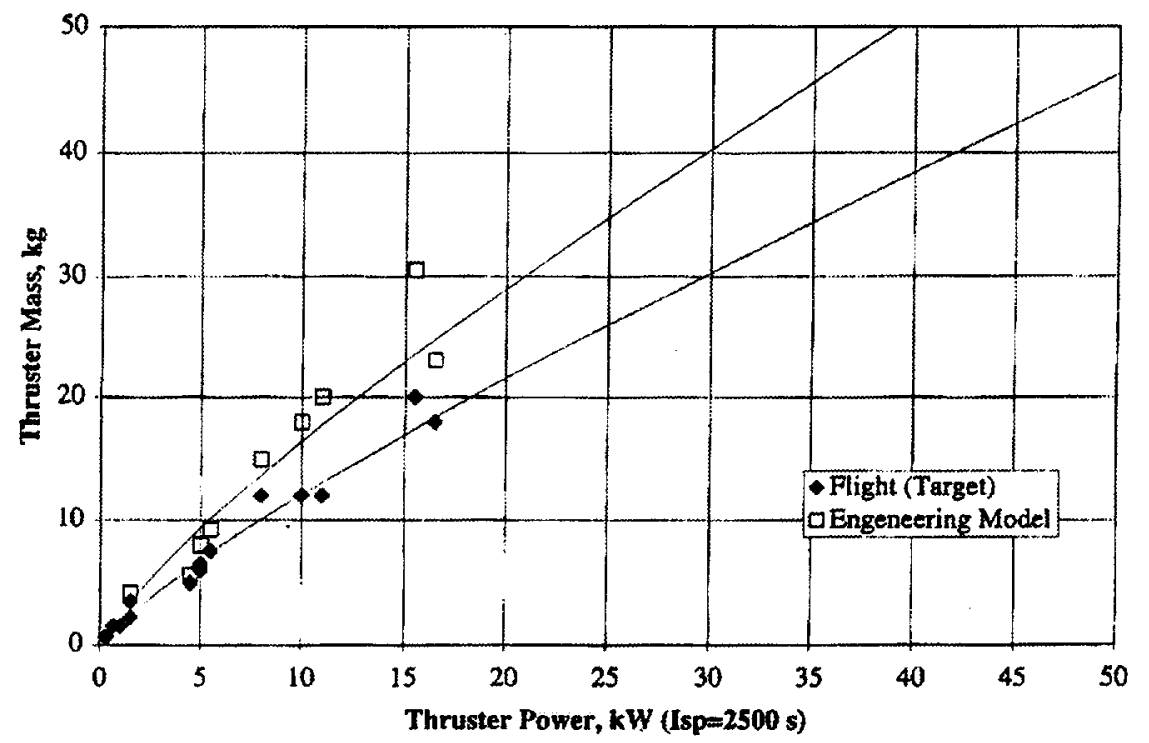

Figure 4: Projected thruster mass versus power for flight and engineering model thrusters 


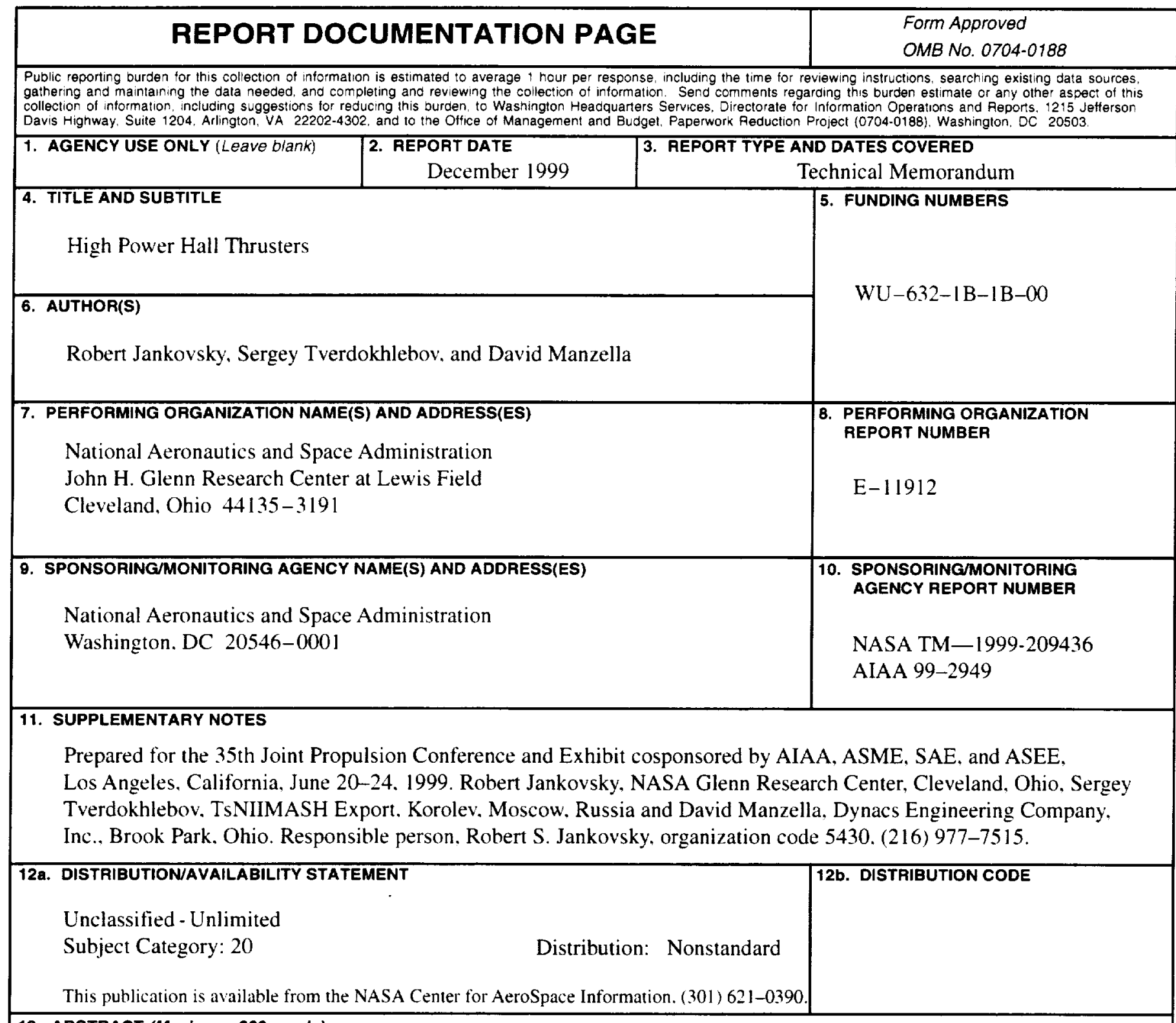

13. ABSTRACT (Maximum 200 words)

The development of Hall thrusters with powers ranging from tens of kilowatts to in excess of one hundred kilowatts is considered based on renewed interest in high power, high thrust electric propulsion applications. An approach to develop such thrusters based on previous experience is discussed. It is shown that the previous experimental data taken with thrusters of $10 \mathrm{~kW}$ input power and less can be used. Potential mass savings due to the design of high power Hall thrusters are discussed. Both xenon and alternate thruster propellant are considered, as are technological issues that will challenge the design of high power Hall thrusters. Finally, the implications of such a development effort with regard to ground testing and spacecraft integration issues are discussed.

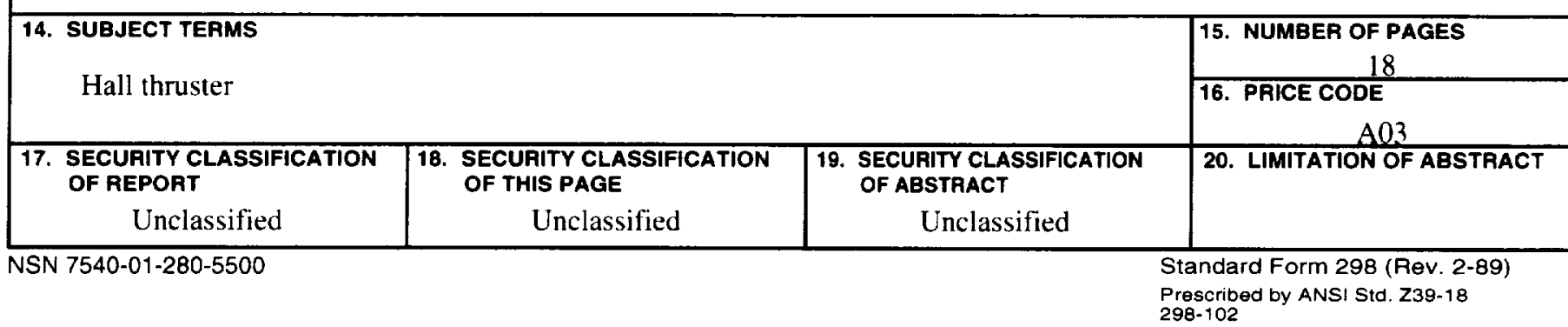

